\title{
LEGENDAÇÃO DE SÉRIES HUMORÍSTICAS: UM ESTUDO DA TRADUÇÃO DO HUMOR NA SÉRIE AMERICANA "FRIENDS"
}

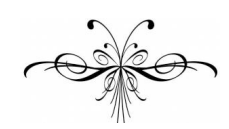

\author{
ELISÂNGELA LIBERATTI
}

\begin{abstract}
Resumo: Partindo-se do princípio de que a legendação de filmes e seriados traz consigo polêmica e controvérsias no que diz respeito às escolhas feitas pelo tradutor, este estudo analisa os procedimentos tradutórios da legendação de seriados cômicos, avaliando-se quais fatores dificultam ou bloqueiam a manutenção do humor no Texto Traduzido. Com isso, foram estudados autores como Vinae e Darbelnet (1997), Barbosa (2002), Zabalbeascoa (1996) e Attardo (2002), realizando-se análise de um seriado norte-americano de grande sucesso. Como resultado, percebeu-se que alguns Textos Traduzidos para seriados cômicos podem não alcançar seu objetivo - o de manter sua comicidade - devido a fatores como: a Língua Fonte produzir um texto na Língua Traduzida que é estruturalmente impossível; diferenças estruturais entre Língua Fonte e Língua Traduzida; diferentes contextos culturais entre Língua Fonte e Língua Traduzida; entre outros. Quando possível, as legendas mantiveram o efeito humorístico, por meio de adaptações ou traduções literais para o Texto Traduzido.
\end{abstract}

Palavras-chave: legendação; procedimentos tradutórios; humor; texto traduzido; texto fonte

\begin{abstract}
The subtitling of movies and sitcoms is something polemic and controversial regarding the choices made by the translator. Thereby, this study analyzes the translation procedures of subtitling comic sitcoms, evaluating which factors hinder or prevent the maintenance of humor in the Translated Text. To achieve this purpose, authors such as Vinae and Darbelnet (1997), Barbosa (2002), Zabalbeascoa (1996) and Attardo (2002) were researched, being performed an analysis of a North American sitcom of great success. As a result, Translated Texts for sitcoms may not reach its objective - of maintaining its comicality - due to factors such as: the Source Language produces a text structurally impossible in the Translated Language; different cultural contexts between Source Language and Translated Language; structural differences between Source Language and Translated Language; etc. When possible, the subtitling kept the humor, through adaptations or literal translations into the Translated Text.
\end{abstract}

Keywords: subtitling; translational procedures; humor; translated text; source text 


\section{Contexto}

legendação de filmes e seriados sempre foi algo polêmico e
questionador, principalmente em relação às escolhas feitas pe-
lo tradutor para certa passagem de texto, uma vez que traduzir é muito mais do que transpor de uma língua para outra.

Traduzir é conhecer o contexto sócio-cultural da audiência que se pretende atingir; é saber que, diversas vezes, línguas podem não ter correspondência formal no processo de passagem da Língua Fonte (LF) para a Língua Traduzida (LT) e lidar com isso, mantendo a tradução mais fiel possível ao Texto Fonte (TF), mas levando-se em consideração o público a que se pretende atingir. Traduzir é, resumidamente, “... uma atividade humana realizada através de estratégias mentais empregadas na tarefa de transferir significados de um código linguístico para outro" (BARBOSA, 1990, p. 11).

Partindo-se do princípio de que há inúmeros fatores a serem levados em conta para realizar-se uma boa tradução, seriados cômicos podem trazer grande dificuldade de tradução, principalmente quando envolvem traduções de textos humorísticos, que, vez ou outra, perdem seu sentido quando transpassados de uma língua a outra.

Com isto, o objetivo de uma piada - gerar riso - algumas vezes é perdido no processo tradutório, e isto pode ser ocasionado por diversos fatores, dentre eles: diferenças nos conhecimentos prévios das audiências do TF e do TT; diferenças de valores culturais e morais, costumes e tradições; diferenças em temas convencionais e técnicas de como contar piadas; o contexto profissional do tradutor; humor verbal dependente de fatores da LF e do contexto visual, entre outros (ZABALBEASCOA, 1996).

Zabalbeascoa (1996) afirma que, em se tratando de tradução de humor, tradutores devem primar por manter o efeito cômico da piada no TT, acima de manter-se totalmente fiel ao TF. Traduções não tão literais, mas que mantenham o efeito irônico, serão mais aceitas pela audiência do TT; piadas não traduzíveis literalmente podem, sem problemas, ser substituídas por piadas que teriam sentido na LT.

Attardo (2002) concorda com Zabalbeascoa (1996) ao apontar que é papel do tradutor substituir, quando necessário, o público alvo zombado no $\mathrm{TF}$, adaptando o estereótipo para o TT e sua respectiva audiência, a fim de se manter o humor presente no TF.

Pelo exposto acima, a tradução do humor é qualitativamente diferente de qualquer outro tipo de tradução e a dificuldade em se criar um conceito de humor pode desencorajar pesquisas nesta área.

No contexto dos estudos da tradução, pouco se sabe sobre os procedimentos utilizados para a tradução de séries humorísticas. Dentro desse contexto, realizou-se um estudo analisando os procedimentos utilizados para a tradução do humor no seriado 'Friends', avaliando-se dados obtidos a partir da transcrição do TF (fala original dos personagens, em Inglês) e da transcrição do TT (legendas em Português). Realizaram-se análises comparativas entre as transcrições dos TF e suas respectivas transcrições dos TT, seguindo as propostas de diversos pesquisadores da área, entre eles Attardo (2002), Barbosa (1990), Catford (1965), Vandaele (2002) e Zabalbeascoa (1996). 
Tendo em vista que a tradução de humor verbal é um processo complexo e, consequentemente, trabalhoso e dificultoso quando se diz respeito a manter-se fiel ao TF e ao mesmo tempo atingir o objetivo principal do humor - o riso, o presente trabalho tem por objetivo investigar alguns dos processos de tradução utilizados no seriado americano 'Friends'.

\section{Legendação}

No que tange aos estudos acadêmicos sobre legendação, pode-se dizer que, no contexto nacional, este campo é relativamente novo, e, talvez por isso, seja comum a confusão gerada em relação às terminologias legendagem e legendação. Enquanto o termo legendagem refere-se à gravação das legendas na fita, ao tempo de aparição de cada legenda, ao tamanho de letra, ao comprimento das frases, entre outros, o termo legendação se refere ao trabalho intelectual do tradutor, aos procedimentos utilizados pelo mesmo para tradução de certa passagem de texto (ARAÚJO, 2002). A legendação faz menção ao trabalho do tradutor, aludindo aos procedimentos adotados pelo tradutor e envolvendo seu trabalho intelectual (Oliveira, 2008).

$\mathrm{Na}$ legendação, é mantido o texto falado original e são acrescentadas legendas traduzidas para a língua alvo, havendo sincronia entre fala e imagem. Se comparada à dublagem (processo em que o texto falado na língua original é substituído por texto falado na língua alvo), a legendação é menos onerosa e, por isso, mais utilizada nos meios audiovisuais (Oliveira, 2008), sendo uma das modalidades de tradução mais praticadas no mundo (Carvalho, 2005, p. 94).

De acordo com Gottlieb (1998) e Linde \& Kay (1999), existem dois tipos de legendação:

- Legendação intralingual (vertical): ocorre dentro da própria língua, sendo destinada a deficientes auditivos. Tem por objetivo substituir o diálogo e outras características importantes de som por uma representação escrita;

- Legendação interlingual (diagonal): feita a partir de uma língua falada para outra na forma escrita, sendo destinada para filmes e programas de língua estrangeira. Tem por objetivo atingir, no TT, algo aproximado ao TF.

Segundo Linde \& Kay (1999), apesar de grandes diferenças entre os dois tipos de legendação existentes, há semelhanças entre a legendação intralingual e a legendação interlingual. São elas:

- Ocorrem no mesmo contexto áudio-visual;

- Envolvem conversão da língua falada para o texto escrito;

- Nas duas formas, a quantidade de diálogo tem de ser reduzida para ir ao encontro das condições técnicas do meio e das capacidades de leitura da audiência.

O presente trabalho enfoca a legendação interlingual, em que a língua falada é a língua inglesa e a língua na forma escrita é a língua portuguesa do Brasil. 
Legendação envolve a integração de texto, som e imagem, a capacidade de leitura da audiência e as restrições espaciais e temporais advindas desses dois fatores. Com isso, legendar é muito mais do que apenas transcrever uma sequência lexical da LF para a LT.

A legendação possui características inerentes aos seus processos tradutórios. Entre estas características, faz-se relevante citar, para o presente estudo (Oliveira, 2008):

- Parte do código oral para o código escrito $\rightarrow$ o código oral tratado no presente estudo são as falas dos personagens do seriado - língua inglesa - e o código escrito são as legendas - língua portuguesa;

- Escreve-se de forma próxima da forma como se expressa oralmente o mesmo enunciado;

- Geralmente, desconhece-se a autoria do texto;

- Submete-se a limitações técnicas $\rightarrow$ entre essas limitações, podem ser citados: tempo de permanência da legenda na tela, limitação de caracteres, curto período disponível para a realização da tradução, tipos de software empregados, exigências do revisor para realizar modificações linguísticas e culturais, sincronia entre a entrada e a saída da legenda e as falas dos personagens, entre outras;

- Muitas vezes, suprimem-se termos considerados de baixo calão, a despeito de estes estarem presentes no texto oral;

- Pode apresentar texto narrativo, descritivo, poético, e, em alguns casos, concomitância de textos.

\section{Humor}

Apesar de diversas tentativas de definições sobre humor, feitas por estudiosos de diferentes áreas, nota-se que este é um conceito subjetivo e abrangente, pelo fato de que há “... uma série de fatores, como cultura, idade, personalidade, educação, região, época e contexto que determinam a percepção do humor" (Koglin, 2008, p. 35).

Segundo o sítio http://campinhoonline.webnode.com.br/news/ohumor/, humor pode ser conceituado como um "... estado de ânimo cuja intensidade representa o grau de disposição e de bem-estar psicológico e emocional de um indivíduo". O humor é elemento vital da condição humana e faz-se essencial para a compreensão de culturas, religiões e costumes das sociedades em amplo aspecto. Aspectos socioculturais normalmente afetam tanto a criação quanto a percepção do humor que, apesar de amplamente estudado, ainda faz-se de difícil definição.

Como se pode perceber, a definição do humor é um tanto subjetiva, demonstrando que o humor é algo ambíguo, relativo e instável.

Com isso, um critério mais simplificado para conceituação do humor faz-se essencial para tradução: quando este atinge um apelo realista e tangível, como, por exemplo, em forma de riso.

De acordo com Vandaele (2002, p. 156 - 157), dois conceitos gerais usados em pesquisas sobre humor são a superioridade e a incoerência. A expli- 
cação desses conceitos segue abaixo (segundo o sítio http://www.portalsaofrancisco.com.br/alfa/fevereiro/dia-do-comediante-3.php):

- Teorias da superioridade - estas teorias partem da hipótese de que o riso é proveniente da sensação de superioridade de um indivíduo frente a outro ou frente a alguma situação. A superioridade pode ocorrer não somente pela diminuição do outro, mas, também, pela depreciação da ética e da moral estabelecidas, como em piadas e trocadilhos que caçoam de regras sociais;

- Teorias da incoerência - nestas teorias, a incoerência é apresentada como força motriz de toda situação cômica, identificando-se como uma experiência frustrada. $\mathrm{O}$ humor é tido como forte dissolução de uma atitude, que é causada pela associação de duas ideias inicialmente distantes. Segundo estes preceitos, o humor de boa qualidade precisará mesclar dois elementos altamente contrastantes de forma que se estabeleça forte relação entres ambos. Para que a piada tenha boa aceitação por parte dos espectadores é fundamental que estes estejam interados das ideias opostas que se apresentam na situação. Da mesma forma, o tradutor deve informar-se sobre os aspectos sócio-culturais do público para que consiga estabelecer relações inusitadas para sua audiência.

\section{Procedimentos de tradução do humor}

De acordo com Vandaele (2002, p. 150), a tradução do humor difere de outros tipos de tradução e, com isso, não se pode escrever sobre tradução do humor da mesma maneira que se escreve sobre outros tipos de tradução. Segundo o autor, tanto textos orientados à prática de como traduzir quanto análises culturais e linguísticas ("Qual o significado da tradução em um contexto específico?") evidenciam a diferença entre tradução de humor e outros tipos de tradução.

Neste contexto, textos de tradução do humor são pobres em relação a uma definição ou descrição do mesmo, especialmente em relação à sua tradução. Vandaele (2002, p. 151) cita que humor não é necessariamente a consequência do sentido literal de uma sentença, sugerindo que "... o humor como equivalente / unidade da tradução precisa ser definido mais adequadamente". (Tradução minha).

A relação entre dois textos - Texto Fonte e Texto Traduzido - capaz de produzir um mesmo efeito ou, pelo menos, similar efeito, denomina-se equivalência da tradução. Para que isto seja possível, deve resultar da reconstrução do TF e de sua recodificação para o TT mantendo-se o mesmo efeito humorístico desejado no TF.

Salvatore Attardo, em seu artigo "Translation and Humour: An Approach based on the General Theory of Verbal Humour", traz diversas definições sobre tradução. Dentre elas, destacam-se duas:

"O processo de mudar o discurso ou a escrita de uma língua (a língua fonte) para outra (a língua traduzida)" Richards et al. (1985), apud Attardo, 2002 , p. 173. Nesse caso, tem-se um significado que se mantém constante entre a Língua Fonte (LF) e a língua traduzida (LT). Attardo (2002) acredita que o ponto crucial - a essência - do processo de tradução seja esta constância entre a 
LF e a LT. Porém, de acordo com os estudos de Saussure, sabe-se que dois enunciados nunca serão exatamente iguais, mesmo em uma mesma língua ou em línguas diferentes. Com isso, o autor faz menção à necessidade de dissociar o processo tradutório de identidade e associá-lo à similaridade.

Chega-se, portanto, a outra definição de tradução "a correspondência entre dois textos, T1 e T2, em que o sentido (S) do T1 (ST1) e o sentido do T2 (ST2) são similares (aproximados)" (ATTARDO, 2002, p. 174. Tradução minha). Contudo, essa definição ainda é simplista, uma vez que ignora os aspectos pragmáticos dos enunciados.

Com isso, Attardo (2002, p. 175. Tradução minha) sugere uma revisão do conceito de tradução acima citado, chegando-se à "correspondência entre dois textos T1 e T2, em que o significado (S) de T1 (ST1) e o significado de T2 (ST2) são similares (aproximados), e / ou a força pragmática (F) do T1 (FT1) e a força pragmática de T2 (FT2) são similares / aproximadas".

As teorias existentes para a tradução do humor incorporam uma teoria de tradução e a aplicam ao humor. Até então, de acordo com Attardo (2002), não havia uma teoria de tradução do humor que fornecesses as ferramentas necessárias para tal. Surge, então, a Teoria do Humor Verbal, que consiste, resumidamente, em afirmar que cada piada é formada por pelo menos um dos seis parâmetros abaixo citados:

Joke: \{LA - Language, NS - Narrative Strategy, TA - Target, SI - Situation, LM - Logical Mechanism, SO - Script Opposition\}

Ou seja, cada piada será composta por um ou mais Script Opposition (SO), nenhum, um ou mais Logical Mechanism (LM), uma ou mais Situations(SI), e assim por diante. Segue abaixo explicação de cada parâmetro e respectivas traduções de seus nomes:

\section{1 - Language (LA) - Linguagem}

Segundo Attardo (2002), a linguagem contém toda a informação indispensável para a verbalização de um texto. Aqui, o conceito de paráfrase faz-se necessário para o entendimento dos tipos de variações da linguagem. Na paráfrase, as palavras são modificadas, mas a idéia do texto original é confirmada pelo novo texto; a menção no novo texto ocorre para atualizar, reafirmar os sentidos ou alguns sentidos do texto referido. É dizer com outras palavras o que já foi dito. Qualquer frase pode ser dita ou escrita de diferentes maneiras, por meio do uso de sinônimos, por exemplo, sem perder sua função semântica. Com isso, piadas que são parafraseadas, preservando seu sentido, são vistas como uma mesma piada.

A linguagem é o parâmetro mais diretamente ligado à tradução literal; com isso, compõe a mais simples abordagem do processo tradutório: substituir linguagem no TF por linguagem no TT.

\section{2 - Narrative Strategy (NS) - Estratégia narrativa}

A estratégia narrativa aponta para o fato de que toda e qualquer piada tem de ser lançada com alguma forma de estratégia narrativa, podendo ser uma 
simples narrativa, um diálogo - perguntas e respostas, um (pseudo) enigma, etc. (ATTARDO, 2002).

Normalmente, não há grande necessidade de se mudar a estratégia narrativa de uma história quando se processa a tradução, uma vez que a organização de uma narrativa é independente da linguagem. Porém, alguns formatos narrativos são únicos a certas culturas e linguagens; nesses casos, o tradutor deve reproduzir a piada alterando a estratégia narrativa do TF, sempre se mantendo o mais próximo possível da estratégia narrativa do texto fonte.

\section{3 - Target (TA) - Alvo}

Como o próprio nome diz, este parâmetro escolhe quem será o alvo da piada. Cada alvo da piada é composto por estereótipos, e, com isso, piadas que não são de cunho agressivo - que não ridicularizam alguém ou algo - não possuem valor para este parâmetro. Por esse motivo, alguns estudiosos podem considerar o parâmetro "Alvo" um parâmetro opcional.

Diferentes culturas possuem diferentes alvos - estereótipos - para seu humor agressivo, sendo que cada grupo alvo é definido por meio de características particulares, como, por exemplo, os italianos, que são considerados sujos e violentos do ponto de vista dos norte-americanos. (ATTARDO, 2002, p. 187).

É papel do tradutor substituir, quando necessário, o público alvo zombado no texto fonte, adaptando o estereótipo para o texto traduzido e sua respectiva audiência, a fim de se manter o humor presente no texto fonte.

\section{4 - Situation (SI) - Situação}

Este parâmetro diz respeito ao fato de que toda piada tem que ter um tema. (ATTARDO, 2002, p. 179). A situação de uma piada pode ser vista como os "acessórios" da piada: seus objetos, participantes, instrumentos, atividades, etc.

Apesar de toda piada ser composta por uma situação, algumas delas ignorarão a situação quase completamente e outras se aterão mais a ela. É possível que o tradutor encontre casos em que a situação não possua correspondente na LF ou, se existente, a situação correspondente não gere reações de humor em sua audiência. Se isso ocorrer, a melhor solução será substituir a situação por outra que gere riso no público alvo.

\section{5 - Logical Mechanism (LM) - Mecanismo Lógico}

Este parâmetro é o mais problemático de todos, sendo o único que não se comporta exatamente como previsto pela hipótese testada na teoria do humor verbal e, segundo Attardo (2002), pode ser considerado um parâmetro opcional.

O mecanismo lógico é independente de linguagem e se faz de simples tradução por esse motivo, uma vez que normalmente é não- verbal e envolve processos lógico-dedutivos e abstratos. Processos que são independentes da linguagem podem, obviamente, ser traduzidos facilmente de uma linguagem para outra. 


\section{6 - Script Opposition (SO) - Oposição de Escrita}

Segundo Attardo (2002), este parâmetro sugere que um texto pode ser caracterizado como piada se as condições abaixo forem atendidas: ferentes;

- O texto é compatível, parcial ou inteiramente, com duas escritas di-

- Essas duas escritas com as quais o texto é compatível são opostas entre si. As duas escritas com as quais algum texto é compatível sobrepõem inteira ou parcialmente o texto.

Escrita (Script) pode ser definida como um organizado complexo de informações sobre algo. Fornece ao falante informações sobre como o mundo é organizado, incluindo sua ação no mundo.

Sobreposição (Overlapping) ocorre durante o processo de combinação de escritas, em que podem surgir textos compatíveis a mais de uma "leitura", encaixando-se a mais de uma escrita. Por exemplo: um texto que descreva alguém acordando, tomando café, deixando a casa, etc. Esses eventos poderiam descrever tanto alguém indo trabalhar quanto alguém saindo para viagem, uma vez que o texto seria compatível com as duas escritas acima citadas. (ATTARDO, 2002).

Se a sobreposição de um texto for total, o texto todo é compatível com as duas escritas e, se a sobreposição for parcial, algumas partes do texto não serão compatíveis com umas das escritas. Ambiguidade, metáforas, textos figurativos, alegóricos, míticos, obscuros e alusivos são exemplos de sobreposição.

A sobreposição de duas escritas não é considerada, necessariamente, razão do humor per se. A segunda condição para um texto ser considerado humorístico é sua oposição, já citada anteriormente. Entende-se por oposição a antonímia local, que pode ser definida por Raskin (1985, p. 108. Tradução minha) como "duas entidades linguísticas das quais os significados são opostos somente em um discurso particular e somente para as propostas do discurso".

Juntamente com o Mecanismo Lógico, a Oposição da Escrita é o parâmetro mais abstrato de todos, uma vez que suas especificações irão variar de acordo com o tempo e o lugar de sua produção. Além disso, cada cultura, cada indivíduo, terá um certo número de escritas que não são apropriadas para virarem piada.

Em Attardo (2002), é citada uma ordem hierárquica dos parâmetros acima mencionados: Linguagem $\rightarrow$ Estratégia Narrativa $\rightarrow$ Alvo $\rightarrow$ Situação $\rightarrow$ Mecanismo Lógico $\rightarrow$ Oposição de Escrita. Isto significa que duas piadas que diferem em Linguagem, por exemplo, são vistas como muito similares entre si, e duas piadas que diferem em Oposição de Escrita são vistas como muito diferentes entre si. Ou seja, a ordem hierárquica é crescente em relação ao grau de diferenciação entre duas piadas.

A partir desta ordem hierárquica, duas piadas que sejam diferentes em suas oposições de escritas são, normalmente, diferentes piadas. Ou seja, o tradutor deve evitar, ao máximo, mudar a oposição de escrita do texto traduzido, fazendo esta mudança somente se a oposição de escrita não existir na língua alvo.

Com isso, o autor sugere uma teoria de tradução de piadas (2002, p. 183. Tradução minha): "Se possível, respeite todos os seis parâmetros em sua 
tradução, mas, se necessário, deixe sua tradução diferir no mais baixo nível necessário para suas propostas pragmáticas".

Attardo afirma que a tradução que respeita todos os seis parâmetros pode ser utópica (tradução absoluta) e a tradução que não respeita nenhum parâmetro não é mais considerada tradução.

Por fim, o autor conceitua a tradução de jogos de palavras (em inglês, "puns" ou "wordplays":

Jogo de palavras é o nome geral para os vários fenômenos textuais nos quais características estruturais da linguagem usada são exploradas com a intenção de trazer uma confrontação comunicativamente significante de duas (ou mais) estruturas lingüísticas com formas mais ou menos similares e com sentidos mais ou menos diferentes (DELABASTITA,1996, p.128, ênfase original).

O autor cita, também, que os efeitos dos jogos de palavras não são, necessariamente, humorísticos, sendo que os jogos de palavras são baseados nas associações de som/significado da linguagem.

Jogos de palavras que possuem características correspondentes no TF e no TT, preenchendo os objetivos pragmáticos da tradução, são traduzíveis, e os que não possuem estas características correspondentes, não o são.

\section{Análise do seriado}

Para análise de tradução do humor verbal, com enfoque em legendação, foi avaliada a quarta temporada da série norte americana 'Friends' (1997/1998). Com isso, foram analisados alguns tipos de humor verbal no ato tradutório texto original / texto traduzido de treze episódios da quarta temporada do seriado.

Feitas as análises detalhadas de quinze cenas contidas nos treze episódios, chegou-se ao cenário exposto a seguir.

Em relação aos procedimentos utilizados na tradução do humor verbal, pode-se dizer que foram encontrados os seguintes nas passagens analisadas (segundo Vinay e Darbelnet (1977)): adaptação, transposição, tradução literal, equivalência e empréstimo. Com isso, o seguinte quadro foi elaborado:

\begin{tabular}{l|l}
\hline \multicolumn{1}{c|}{ Tradução direta } & \multicolumn{1}{c}{ Tradução oblíqua } \\
Tradução literal: 6 casos & Adaptação: 2 casos \\
Empréstimo: 2 casos & Transposição: 1 caso \\
& Equivalência: 4 casos \\
\hline
\end{tabular}

Quadro 1: Procedimentos de tradução direta e tradução oblíqua segundo Vinay e Darbelnet (1977)

No que diz respeito aos textos humorísticos em que a comicidade não se manteve no TT, nove das quinze passagens analisadas certamente acabaram por ter seu efeito cômico prejudicado de alguma forma. Os motivos para tal são: 
- A LF produz um texto na LT que é estruturalmente impossível:

\section{Transposição}

Chandler está na sala de Joanna, mas ninguém pode saber que ele está lá. Quando o telefone toca, Chandler atende, dizendo:

Chandler - TT: "Alô, Joanna... é do escritório dela".

(TF: Hello, Joanna...'s office).

Apesar de o sentido do texto ter sido mantido, perdeu-se seu efeito cômico, uma vez que este se dá pelo fato de Chandler conseguir corrigir o deslize ao rapidamente adicionar o 's office depois do nome "Joanna". Isto não se faz possível na estrutura da língua portuguesa.

\section{Tradução literal}

Monica para os funcionários - TT: "De agora em diante, vai ser como eu quero ou então é rua".

(TF: From now on, it's going to be my way or the highway).

O seriado brinca com as palavras "my way" e "highway"; contudo, este jogo de rimas não é possível no TT.

- A LF não tem correspondência no contexto cultural da LT:

\section{Tradução literal}

Joey treina dança de salão com o zelador do prédio, sendo seu parceiro de dança. Nesta cena, Joey conta para Rachel e Monica sobre o ocorrido.

Monica - TT: "Parceiro de dança?"

(TF: Dancing partner?)

Joey - TT: "Haverá uma festa de zeladores... uma super festa... e elequer impressionar a zeladora Marge".

(TF: Yes, there's this superintendence dance... 'The super-ball'... and he wants to impress Marge, this lady super that he's got a crush on).

"Super-ball" refere-se tanto à tradução que foi feita - super baile/festa quanto à 'super-ball', um brinquedo popular nos Estados Unidos. O trocadilho não funciona para a cultura brasileira, pois esta bolinha, no Brasil, é chamada 'bolinha pula-pula', e, para os espectadores brasileiros que não conhecem o nome da bolinha em inglês, a piada de duplo sentido acaba perdendo um de seus sentidos.

- O texto que a LF produz na LT não tem significado:

\section{Tradução literal}

Monica está pessimista quanto a preparar um jantar para um funeral. Com isso, Phoebe diz que Monica está muito negativa e isso não é atitude que se espera dela.

Pheebs - TT: "Porque está tão negativa?".

(TF: Wow, what's it with all the negativity?).

TT: "Não parece coisa de Monica".

(TF: You sound like Moni can't, not Moni can).TT: "Moni-ca"

(TF: Moni-ca). 
Quando Pheebs diz "Moni can", referindo-se ao fato de a Monica ser capaz de fazer o jantar (can = pode), ocorre um trocadilho com o nome da Monica que não se faz possível na língua portuguesa. Na língua inglesa, o nome da Monica é pronunciado por Phoebe nesta frase como 'Moni-can', referindo-se a algo como 'Monica pode', ou seja, há uma inserção de uma palavra (can) em um nome (Monica). Depois disso, ela se lembra de que o nome da Monica não é 'Moni-can' e sim 'Moni-ca' e faz a correção. Este jogo de palavras não faz sentido quando traduzido para a língua portuguesa, uma vez que o verbo inglês "can" não é nada parecido com o verbo "poder", que é sua tradução para o português.

- A ironia causada pela ambigüidade do TF faz-se impossível no TT, uma vez que o TT possui somente um dos dois sentidos plausíveis no TF. O TT não permite o duplo sentido obtido pelo TF:

\section{Adaptação}

Joey - TT: "Pessoal! Vejam só isso! Adivinhem o emprego que arrumei!" (TF: Hey, you guys, check it out, check it out. Guess what job I just got) Chandler - TT: "Eu não sei, mas Donald Trump quer que "revolva" seu terno azul".

(TF: I don't know, but Donald Trump wants his blue blazer black).

Na língua inglesa, a graça da brincadeira encontra-se no fato de Chandler dizer "black" ao invés de "back", e também pelo fato de ele dizer "Blue blazer black", enrolando-se com a palavra "back" por causa das duas primeiras palavras que falou, que começam com "bl". Este é um jogo de palavras que brinca com cores, o qual se faz impossível traduzir para o português sem ser perdido. Apesar de o tradutor ter tentado manter o efeito cômico da piada, usando o termo inventado "revolva" no lugar da palavra "devolva", ela continua sem nexo na legendação em português, uma vez que não permite o duplo sentido obtido com as palavras em inglês "black" e "back".

\section{Tradução literal}

Rachel está com um cliente, pelo qual se apaixona, e quando vai vender as roupas da loja em que trabalha, diz:

Rachel - TT: "Vamos começar. Vou mostrar minhas cuecas".

(TF: Let's get started. I'll show you my underwear).

Na língua inglesa, "underwear" pode referir-se tanto à roupa íntima masculina quanto à feminina. No caso, a graça da piada está em parecer que Rachel se oferece para mostrar suas roupas íntimas. O tradutor optou por traduzir "underwear" como cuecas, que, apesar de ser uma tradução literal e manter o sentido da fala da personagem, perde a ambigüidade do que é dito por Rachel, pois ela não usa cuecas. Se a tradução fosse "roupas íntimas" ao invés de "cueca", a piada não teria perdido seu sentido cômico.

\section{Tradução literal}

Mônica para Ross - TT: "Nossa, isso foi... espetacular"

(TF: Wow, that was... terrific).

Ross decide tocar para seus amigos umas "músicas" que ele tinha feito quando jovem. No fim das contas, as melodias não eram nada agradáveis e, da 
primeira vez que ele toca, todos ficam espantados. Na língua inglesa, "terrific" pode significar tanto "sensacional/formidável/espetacular" quanto "terrível/espantoso", dependendo do contexto da situação. Monica usa este adjetivo para agradar Ross, ou seja, quer que ele entenda que a apresentação foi "espetacular", mas na verdade o que ela quer dizer sobre a música é que foi "terrível".

- O texto que a LF produz na LT não tem correspondência no mesmo registro:

\section{Tradução literal}

Joey está em uma gravação e está cheirando muito mal. Discretamente, decide ir se lavar. Quando seu chefe entra em seu camarim, encontra Joey tomando banho e eles têm a seguinte conversa:

Joey - TT: "Olhe, sinto muito, mas eu estava mal".

(TF: Anyway, I'm sorry, but I just... I stink)

Charlton Heston - TT : "Todo ator, vez ou outra... todo ator acha que não está bem".

(TF: Every actor, one time or another... every actor thinks he stinks).

TT: "Não conheço nenhum ator de respeito que ao menos uma vez em sua carreira não tenha dito 'Droga, não estou bem'".

(TF: I don't know any actor worth his salt who, one time in his career, didn't say 'God, I stink').

TT: "Mas, o importante, lembre-se sempre...não importa o quanto ache que não está bem... você nunca, nunca deve invadir meu camarim e usar meu chuveiro".

(TF: But, the important thing, you must remember, no matter how badly you think you stink, you must never, ever, bust in to my dressing room and use my shower.

Em português, fica impossível manter a ironia do jogo de palavras com a tradução literal, uma vez que, na lingual inglesa, "stink" pode significar tanto cheirar mal - sentido literal - (que era o que Joey queria dizer) quanto não ter bom desempenho em algo - sentido metafórico (que era o que o chefe entendeu). O tradutor, por vez, não teve como brincar com o jogo de palavras 'cheirar mal' e 'não ter bom desempenho em algo'.

- O texto que produzido na LT tem significado diverso do TF:

\section{Tradução literal}

Rachel - TT: "Estou tão pra baixo".

(TF: I feel blue.)

O efeito cômico desta cena consiste no fato de Rachel estar usando uma saia azul no momento em que diz a frase. Com isto, o humor do TF se daria pelo fato de ela estar de roupa azul (blue) e sentindo-se para baixo (também 'blue', em língua inglesa). "I feel blue" não permite tradução literal, uma vez que "Sinto-me azul" (tradução literal de "I feel blue") não corresponde ao significado da LF, que quer dizer "Estou para baixo". 
Das quinze passagens analisadas, três dependem do conhecimento cultural e de mundo da audiência para que o efeito cômico do TT seja mantido ou não. Os motivos para essa dependência são:

- Os leitores do TLT entendem - ou não - a diferença existente entre "soccer" (inglês americano) e "football" (inglês britânico) e seus significados em língua inglesa:

\section{Empréstimo}

Quando um dos rapazes da cena demonstra que já tinha ficado com Emily (a namorada de Ross), Ross sente-se enciumado e faz uma brincadeira em relação ao inglês britânico:

Ross para os rapazes - TT: "Estavam jogando 'soccer', ou devo chamar de 'football'?"

(TF: So, were you guys playing soccer, or should I call it football?).

Para que se mantivesse o humor deste jogo de palavras, o tradutor optou por acreditar que os leitores do TLT entenderiam a diferença existente entre "soccer" (inglês americano) e "football" (inglês britânico), além de achar que entenderiam seus significados em língua inglesa.

- O TF tem ou não correspondência no contexto cultural da LT - se o espectador não conhecer a banda citada, não entenderá o humor das frases:

\section{Tradução literal}

Apaixonado por Emily, Ross coloca um brinco na orelha para agradá-la. Ao se encontrar com seus amigos, Chandler e Joey, os surpreende por estar usando o brinco. Chandler faz um comentário irônico:

Chandler - TT: "Sabia que o "Wham!" terminou?

(TF: You do know that Wham! Broke up?)

A tradução do TF para o TT foi feita de maneira a se manter o sentido da piada, utilizando-se de tradução literal; porém, a intenção almejada pelo humor pode não ser alcançada, dependendo do nível cultural do espectador. Se a audiência - no caso, Brasil - não souber quem foi a banda inglesa "Wham!", a piada não terá o efeito cômico desejado. Neste caso, o que pode ocorrer é que talvez o TF não tenha correspondência no contexto cultural da LT (1990). O tradutor, contudo, não achou necessária substituição por alguém mais familiar ao público brasileiro (por exemplo, um famoso cantor brasileiro que usasse brinco na época).

\section{Empréstimo}

Ross agradece uma ajuda dos amigos Chandler e Joey, e Chandler diz, para zombar do brinco de Ross:

Chandler - TT: "Não foi nada".

(TF: Ok, no problem).

TT: "Mas não esqueça de "Wake me up before you go-go"”

(TF: Just remember to wake us up before you go-go). 
Como já citado, o texto pode não atingir o humor desejado se a audiência não conhecer a banda "Wham!" e suas músicas de maior sucesso. Chandler utilizou o nome da música "Wake me up before you go-go" para tirar sarro de Ross, adaptando um pouco este nome para dar sentido à frase: "Just remember to wake us up before you go-go". Já no caso do TT, esta adaptação não se faz possível, tendo o tradutor optado por mixar a língua portuguesa e a língua inglesa na mesma sentença.

Para finalizar a análise, três das quinze passagens estudadas não perderam seu efeito cômico no ato tradutório, uma vez que o legendador optou por usar equivalentes e adaptações da LF. As razoes para esta manutenção são as abaixo demonstradas:

- Adaptação do TF para a cultura do TT, mantendo o sentido e o efeito cômico da frase:

\section{Adaptação}

Ross critica e corrige o jeito com que Rachel escreveu uma parte de uma carta:

Ross: TT - "A propósito, 'pôr' com acento significa colocar e sem acento é preposição".

(TF: By the way, Y-O-U-apostrophe-R-E means 'you are'. Y-O-U-R means 'your"').

- Equivalência do TF para a cultura do TT, mantendo-se o sentido e o efeito cômico da passagem de texto:

\section{Equivalência}

Rachel sente ciúmes da namorada de Ross (pois gosta de Ross).

Julie - TT: "Fizemos pós-graduação juntos"

(TF: Ross and I were in grad. school together)

Ross - TT: "Não a via desde então"

(TF: We haven't seen each other since then)

TT: "Quando cheguei lá, adivinhem quem dirigia a escavação?

(TF: When I land in China, guess who's in charge of the dig?)

Rachel - TT: "Julie! Isn't that great?"

(TF: Julie! Não é demais?)

TT: "Vou lhe dar um chute no saco de tão fantástico que é"

(TF: I mean, isn't that just kick-you-in-the-crotch, spit-on-your-neck fantastic?)

- Equivalência do TF ao TT, adequando-se à realidade extralinguística brasileira:

\section{Equivalência}

Janice conta que está divorciada e enfatiza que está solteira (pois tem interesse em Chandler, que está no ambiente no momento da conversa).

Monica - TT: "Como você está?

(TO: How have you been?) 


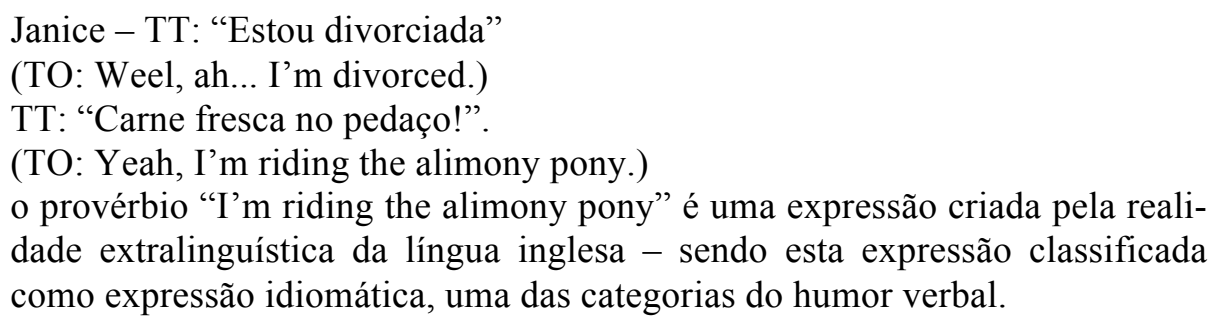

Como se pode observar no quadro um, o procedimento de tradução mais utilizado nas passagens analisadas da série foi a tradução literal (6 ocorrências), seguido pela equivalência (4 ocorrências). Conforme já citado anteriormente, nem todos os procedimentos e estratégias utilizados pelo tradutor foram os mais adequados. Dentro do possível, algumas soluções e sugestões para uma melhor tradução foram mencionadas no presente estudo.

\section{Conclusão}

O tema abordado no presente estudo foi a legendação de filmes e seriados internacionais. A decisão em estudar este assunto deve-se ao fato de este ser um tópico polêmico, uma vez que a escolha feita para a tradução de uma passagem de texto depende de cada tradutor. Com isso, não há formula pronta para se dizer qual a melhor maneira para a tradução de uma língua (LF) a outra (LT).

Outro ponto que torna este tema polêmico, e, com isto, objetivo desta pesquisa, é o fato de que, em seriados cômicos, existem diversas características que podem trazer empecilhos à tradução. A principal delas é a dificuldade de manutenção do efeito cômico quando piadas são transpassadas de uma língua a outra, devido a diferenças nos conhecimentos prévios das audiências do TF e do TT; diferenças de valores culturais, costumes e tradições; contexto profissional do tradutor, etc. (ZABALBEASCOA, 1996).

Conforme citado anteriormente, existem diversas classificações e modelos de tradução, todos com um objetivo em comum: “... transferir significados de um código linguístico para outro” (BARBOSA, 1990, p. 11).

É neste contexto que são feitas análises dos procedimentos tradutórios no seriado americano 'Friends', buscando diagnosticar se os procedimentos escolhidos pelo legendador mantêm a tradução o mais fiel possível ao TF, conservando-se, também, seu efeito cômico. Além disso, são feitas algumas sugestões de legendação, nos casos em que a tradução escolhida não foi a mais ideal em minha opinião - devido ao fato de perder-se o efeito humorístico de tal passagem.

\section{Sugestões de pesquisa futura}

Devido ao fato de que, no contexto dos estudos da tradução, não muito foi pesquisado sobre os procedimentos utilizados para a tradução de séries humorísticas, sugere-se que mais análises deste tipo sejam realizadas. Com isto, mais conteúdo será acrescentado aos (poucos) estudos já existentes na área de legendação do humor verbal. A partir disso, será possível a criação de modelos 
para tal trabalho, aperfeiçoando as legendas de séries humorísticas, de modo que estas se mantenham fiéis ao Texto Fonte e ao mesmo tempo não percam sua comicidade.

\author{
Elisângela Liberatti \\ elisliberatti@hotmail.com \\ Universidade Federal de Santa Catarina
}

\title{
Referências bibliográficas
}

ARAÚJO, V.L.S. Glossário bilíngue de clichês para legendagem e dublagem. The ESPecialist, v.23, n.2.2002. p. $139-154$

AtTARDo, Salvatore. Translation and Humour: An Approach based on the General Theory of Verbal Humour (GTVH). In: The translator, volume 8, number 2 (2002). 173 - 194.

BARbosa, Heloisa Gonçalves. Procedimentos técnicos da tradução - uma nova proposta. Campinas: Editora Pontes, 1990.

Besien, Fred Van; Pelsmaekers, Katja. Subtitling Irony - Blackadder in Dutch. In: The Translator. Volume 8, Number 2 (2002), p. 241 - 266.

CARvalho, C.A. A tradução para legendas: dos polissistemas à singularidade do tradutor. 2005. 157 f. Dissertação (Mestrado em Estudos da Linguagem) - Pós-graduação em Estudos da Linguagem, Pontifícia Universidade Católica do Rio de Janeiro, Rio de Janeiro.

CATFORD, J.C. - A linguistic theory of translation. Oxford, Oxford University, 1965. 103p.

. Uma teoria linguistica da tradução. São Paulo. Cultrix/Universidade Católica de Campinas, 1980. 121p. Tradução do Centro de Especialização de Tradutores da Pontifícia Universidade Católica de Campinas.

Chesterman, Andrew; Williams, Jenny. The map - A Beginner's Guide to Doing Research in Translation Studies. Manchester, UK: St. Jerome Publishing, 2002.

Delabastita, Dirk (ed) (1996) Wordplay and Translation, Manchester: St. Jerome.

Gottlieb, H. In: M. BAKer. Routledge Encyclopedia of Translation Studies. London / New York: Routledge, 1998. p. 244 - 248.

Koglin, Arlene. A tradução de metáforas geradoras de humor na série televisiva Friends: um estudo de legendas. 2008. 99f. Dissertação (Mestrado em Estudos da Tradução) - Pós-graduação em Estudos da Tradução, Universidade Federal de Santa Catarina. Florianópolis - SC. 
Linde, Zoe de \& KaY, Neil. The Semiotics of Subtitling. Manchester: St. Jerome Publishing, 1999, $107 \mathrm{pp}$.

MARKUSKI, L. A. Da fala para a escrita: atividades de retextualização. $7^{\mathrm{a}}$ edição. São Paulo: Cortez, 2007.

OliveIRA, Sila Marisa de. Legendação de metáforas: um estudo empíricoexperimental com base no filme "La lengua de las mariposas". 2008. 101 f. Dissertação (Mestrado em Estudos da Tradução) - Pós-graduação em Estudos da Tradução, Universidade Federal de Santa Catarina, Florianópolis, SC.

RASKIN, Victor. Semantic Mechanisms of Humor, Dordrecht, Boston \& Lancaster: D. Reidel (1985).

VAndaele, Jeroen. (Re-)Constructing Humour: Meanings and Means. In: The translator, volume 8, number 2 (2002). $149-172$.

VÁZQUES-AYORA, Gerardo - introducción a la traductologia: curso básico de traducción. Washington Georgetown University, 1977. $471 \mathrm{p}$.

VinAY, J.-P. e DARBELNET, Jean - Stylistique compare du français et de l'anglais; Méthode de traduction. Paris, Didier, 1977. Nova edição revista e corrigida. Primeira edição: 1958.

ZabalbeascoA, Patrick. Translating Jokes for Dubbed Television - Situation Comedies. In: The translator, volume 2, number 2 (1996). 235 - 257.

\section{Sítios consultados}

http://recantodasletras.uol.com.br/forum/index.php?action=printpage;topic $=360$ 2.0

http://www.radames.manosso.nom.br/retorica/trocadilho.htm

http://hunch.com/vintage-toys/bouncy-ball/3203684/

http://michaelis.uol.com.br/moderno/portugues/index.php?lingua=portuguesportugues\&palavra $=$ trocadilho

http://www.anedotas.rir.com.pt/estudos_conceitos_anedotas.php\#Trocadilhos

http://recantodasletras.uol.com.br/teorialiteraria/1608259,

http://www.letras.com.br/biografia/friends

http://www.infopedia.pt/\$antanaclase

http://campinhoonline.webnode.com.br/news/o-humor/, http://www.portalsaofrancisco.com.br/alfa/fevereiro/dia-do-comediante-3.php

http://www.schools.nsw.edu.au/raps/eggsactly/glossary.htm

http://www.infoescola.com/portugues/intertextualidade-parafrase-e-parodia/

http://www.lastfm.com.br/music/Wham!/ 